\title{
Analysis of Basic Students Learning Difficulties in Multiple Materials
}

\author{
Silvy Yulistia Salsabila, Geri Syahril Sidik, Rizki Hadiwijaya Z
}

Universitas Perjuangan Tasikmalaya

yulistiasilvy9@gmail.com

\section{Article History}

accepted 05/11/2020

approved 10/11/2020

published 01/02/2021

\begin{abstract}
This study aims to obtain an overview of learning difficulties. This research was conducted in third class of SDN 2 Cintaraja. The research method used is descriptive qualitative. The data collection technique was carried out in two ways, namely by giving story questions and interviews. The story questions used in this study were three questions which refer to four characteristics of student learning difficulties according to Jamaris in 2014 (weakness in counting, difficulty in transferring knowledge, understanding of mathematical language, difficulty in visual operations) regarding the multiplication. The results showed that there were still many students who had learning difficulties in this multiplication material, of the six students who were sampled all of them were only able to master one characteristic of the four characteristics of learning difficulties, namely in terms of understanding the language of mathematics, while the other three learning difficulties had not able to be mastered by them, namely in terms of calculating weaknesses, difficulties in transferring data, and difficulties in visual operations of the multiplication material.
\end{abstract}

Keywords: descriptive qualitative, student learning difficulties, and mathematical multiplication

\begin{abstract}
Abstrak
Penelitian ini bertujuan untuk memperoleh gambaran tentang kesulitan belajar. Penelitian ini dilaksanakan di kelas III SDN 2 Cintaraja. Metode penelitian yang digunkan adalah kualitatif deskriptif. Teknik pengumpulan data dilakukan dengan dua cara yakni dengan memberikan soal cerita dan wawancara. Soal cerita yang digunakan dalam penelitian ini sebanyak 3 soal yang mengacu pada 4 karakteristik kesulitan belajar siswa menurut Jamaris tahun 2014 (kelemahan dalam berhitung, kesulitan dalam mentransfer pengetahuan, pemahaman bahasa matematika, kesulitan dalam operasi visual) mengenai materi perkalian. Hasil penelitian yang diperoleh bahwa masih banyak siswa yang memiliki kesulitan belajar pada materi perkalian ini, dari keenam siswa yang dijadikan sampel penelitian mereka semua hanya mampu menguasai 1 karakteristik dari 4 karakteristik kesulitan belajar yaitu dalam hal pemahaman bahasa matematika, sedangkan 3 kesulitan belajar lainnya yang belum mampu dikuasai oleh mereka yakni dalam hal kelemahan menghitung, kesulitan dalam mentransfer data, dan kesulitan dalam operasi visual materi perkalian.
\end{abstract}

Kata kunci: kualitatif deskriptif, kesulitan belajar siswa, dan perkalian matematika

Social, Humanities, and Education Studies (SHEs): Conference Series https://jurnal.uns.ac.id/shes

p-ISSN 2620-9284

e-ISSN 2620-9292 


\section{PENDAHULUAN}

Matematika merupakan salah satu mata pelajaran yang dianggap menakutkan bagi sebagian siswa, karena dalam prosesnya siswa melakukan banyak perhitungan dan logika menurut Mutaqin (2017). Salah satu hal kecil yang membuat matematika menjadi mata pelajaran yang sulit adalah perkalian.Berdasarkan hasil observasi kepada siswa kelas III Sekolah Dasar dan wawancara dengan wali kelas, ternyata dalam mengerjakan soal perkalian masih banyak siswa yang memberikan jawaban tidak sesuai dengan harapan. Lembar tes perkalian yang diberikan adalah "di kelas IV terdapat 12 buah meja. Ada berapa jumlah kaki meja yang terdapat di kelas IV?". Dari hasil tes sederhana tersebut peneliti mendapatkan beragam jawaban. Kebanyakan siswa tidak memiliki konsep untuk memecahkan permasalahan yang didapatkannya.

Pada pengerjaan soal tersebut beberapa siswa memberikan jawaban terbaiknya dengan teknik menggambarkan 12 meja beserta kaki meja tersebut sebanyak 24 . Seperti gambar dibawah ini:

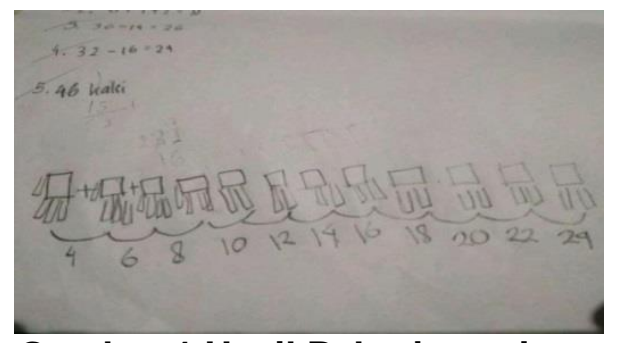

\section{Gambar 1 Hasil Pekerjaan siswa}

Hasil yang diberikan pada gambar 1 adalah menggambarkan 12 meja beserta kaki- kaki meja, tetapi pada saat menjunmlahka seluruh kaki meja yang ada dengan teknik kelipatan siswa memberikan jawaban sebanyak 24, bukan menjawab 48 kaki meja.

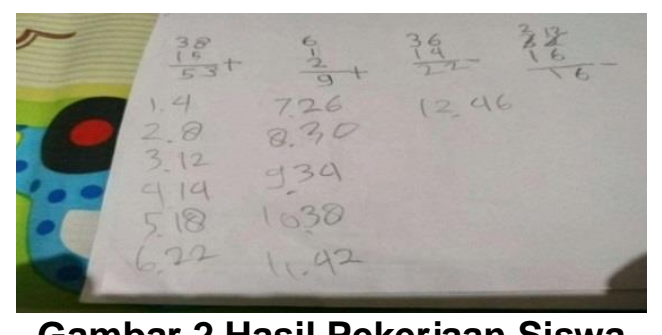

Hasil yang diberikan pada gambar 2 adalaha menyusun beberapa angka siswa lebih mengurutkan beberapa angka 1-12, kemudian mengurutkan kelipatan 4, tetapi pada saat urutan angka ke 4 terjadi kesalahan sehingga jawaban yang didapatkan hanya 46 , sedangkan jawaban yang benar adalah 48 .

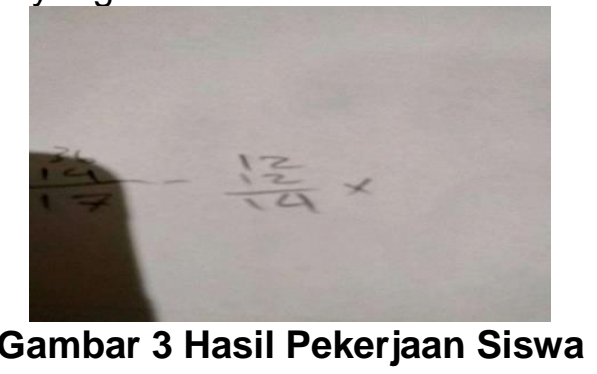

Hasil yang diberikan pada gambar 3 adalah siswa menggunakan teknik perkalian susun tetapi belum mengetahui teknik penerapannya seperti apa, dapat dilihat bahwa saat mengalikan angka 12 dengan 12 polanya seperti ini $\left(12 \times 12={ }_{-}\right)$, 
siswa memberikan hasil sebanyak 14 yang seharusnya 144, tetapi tetap saj salah karena hasil yang diinginkan adalah 48 .

Menurut Yeni (2015), karakter yang dimiliki setiap anak sangatlah beragam seperti hal nya kemampuan akademis, yang dimana kemampuan setiap anak pasti berbeda tingkatannya.

Hasil yang didapat adalah perlu adanya identifikasi atau analisis yang mendalam terkait kesulitan belajar siswa agar mengetahui hal dasar dimana letak kesulitan siswa dalam penyebab kesulitan tersebut dan kedepannya pendidik dapat mempunyai suatu gambaran untuk merancang bahan ajar yang mendasar pada kesulitan siswa. Maka dari itu, peneliti tertarik untuk melakukan penelitian dengan judul: "Analisis Kesulitan Belajar Siswa Sekolah Dasar Pada Materi Perkalian".

\section{METODE}

Penelitian ini menggunakan teknik penelitian kualitatif, yakni penelitian yang bersifat deskriptif dan cenderung menggunakan analisis.Penelitian ini bertujuan untuk memaparkan kesulitan belajar siswa mengenai materi perkalian dengan cara pemberian tes dan wawancara secara lansung kepada 6 siswa sebagai sampel mengenai pemahaman dari jawaban yang diberikan siswa.

Kegiatan ini diharapkan agar permasalahan yang sering terjadi mengenai kemampuan aritmatika dasar yakni perkalian tidak terulang kembali.

\section{HASIL DAN PEMBAHASAN}

Hasil penelitian yang dilakukan terhadap 6 subjek siswa Sekolah Dasar yang diberikan tes mengenai materi perkalian beserta kegiatan wawancara sebagai berikut:

1. Soal Pertama $\left(Q_{1}\right)$

Q1 "Silvy memiliki beberapa kantong permen. Setiap kantong berisi 5 buah. Jumlah permen yang dimiliki Silvy ada 20 permen. Berapa kantong permen yang Silvy punya?"

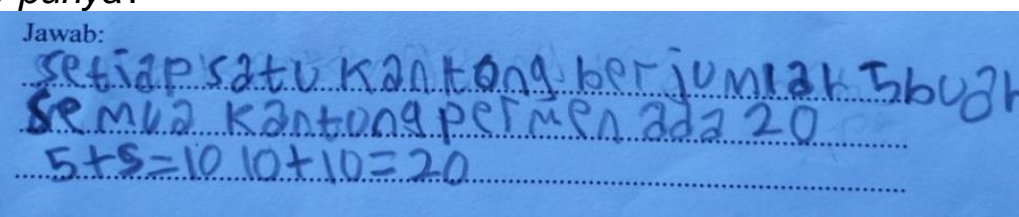

\section{Gambar Hasil Pekerjaan $\mathbf{S}_{\mathbf{1}}$}

Pada penyelesaian Q1, S1(siswa berkemampuan matematika rendah) menjawab dengan cara menguraikan dalam bentuk kalimat dan angka tetapi dengan cara penjumlahan, dengan cara menjumlahkan angka $5+5=10$ dan yang satu lagi $10+10=20$. Hal ini dapat dilihat dari hasil wawancara dengan $S_{1}$ sebagai berikut:

$P \quad$ Bagaimana cara kamu mengerjakan pertanyaan nomor satu ini?

$S_{1} \quad$ Ya ditambah- tambahin aja bu. (sambil melihat lembar pertanyaan)

$P \quad$ Apa jawabannya sudah betul?

$S_{1} \quad$ Sudah bu hehehehe (sambil tertawa)

Sudah terlihat bahwa $S_{1}$ kebingungan dalam memahami soal yang diberikan dan cara mengoprasikan perkalian dalam bentuk penjumlahan yang diuraikan.

2. Soal Kedua $\left(Q_{2}\right)$

Q2 "Silvy memiliki 5 buah kantong permen. Setiap kantong berisi 3 buah permen. Berapa jumlah semua permen yang Silvy miliki?"

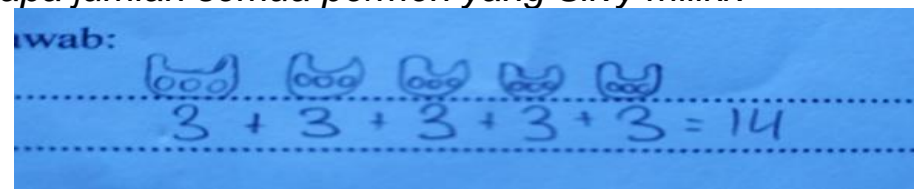

Gambar Hasil Pekerjaan $\mathbf{S}_{6}$ 
Pada $\mathrm{Q}_{2}, \mathrm{~S}_{6}$ (siswa berkemampuan matematika tinggi) menjawab berbeda dengan teknik yang digukan sebelumnya, kali ini $S_{6}$ menggambarkan 5 kantong yang berisi 3 buah permen disetiap kantongnya sesuai dengan yang diperintahkan dalam soal. Tetapi kali ini S6 menjawab tidak sesuai dengan apa yang diharapkan, yakni menjawab seluruh permen yang dimiliki Silvy sebanyak 14 buah permen. Hal tersebut dapat dilihat dari wawancara berikut:

$P \quad$ Di nomor dua ini kamu menjawab berapa isinya?

$S_{6} \quad 14$ permen semuanya

$P \quad$ Apa sudah benar jawabannya?

$S_{6} \quad$ Betul meureun hehehe (meren dalam bahasa indonesia itu mungkin)

Sebenarnya S6 disini hanya keliru dalam menentukan hasil akhir yang ditentukan.

3. Soal Ketiga $\left(Q_{3}\right)$

Q3 "Silvy memiliki 3 kantong permen. Jumlah seluruh permen yang dimiliki Silvy sebanyak 12 buah permen. Berapa jumlah permen yang ada disetiap kantong Silvy?"

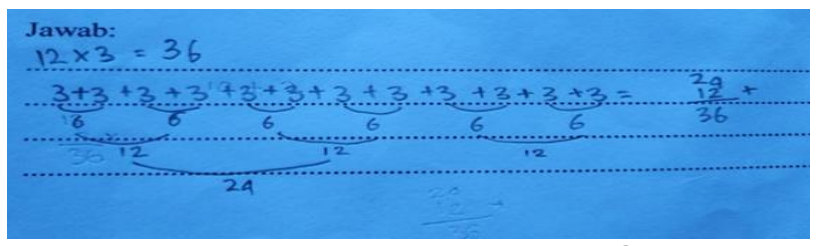

Gambar Hasil Pekerjaan $\mathbf{S}_{6}$

Pada $Q_{3}, S_{6}$ (siswa berkemampuan matematika sedang) menggunakan teknik penjumlahan berderet dengan menderetkan angka 3 kemudian dijumlahkan dengan cara mengelompokannya jadi 6 dan ditambahkan kembali jadi 12 sampai mendapatkan hasil 36. Hal tersebut dapat dilihat dari wawancara sebagai berikut:

$P \quad$ Bagaimana cara kamu menjawab nomor 3 ini?

$S_{5} \quad$ hehehehe (hanya tertawa sambil menunduk)

Dari sini kita dapat mengatakan bahwa S5 masih belum memahami mengenai materi perkalian.

Dari hasil penelitian yang dilakukan terhadap 6 subjek siswa Sekolah Dasar yang dapat didilihat dalam suatu tabel serta dibahas dalam bentuk deskriptif sebagai berikut:

1. Pertanyaan Pertama $\left(Q_{1}\right)$

\section{Tabel 1. Hasil Jawaban Q1}

\begin{tabular}{cl}
\hline Subjek & \multicolumn{2}{c}{ Kesulitan } \\
\hline $\mathrm{S}_{1}$ & Menjawab dengan cara pertambahan $5+5=10$ kemudian \\
& $\begin{array}{l}10+10=20, \text { sehingga jawaban } S 1 \text { adalah } 20 . \text { Jawaban yang } \\
\text { diharapkan adalah } 4 \text { kantong permen. }\end{array}$ \\
\hline
\end{tabular}

Pada pengerjaan soal pertama (Q1), subjek satu (S1) masih jauh tertinggal pemahamannya dalam mengerjakan lembar soal yang telah diberikan. Kesulitan matetika yang dialami oleh $\mathrm{S}_{1}$ kali ini bukan hanya kelemahan dalam berhitungnya saja, tetapi dalam kesulitan mentransfer pengetahuan juga. Jawaban yang diberikan oleh $\left(S_{1}\right)$ yakni $(5+5=10)$ dan $(10+10=20)$.

2. Pertanyaan Kedua $\left(Q_{2}\right)$ 
Tabel 2. Hasil Jawaban Q2

\begin{tabular}{|c|c|}
\hline Subjek & Kesulitan \\
\hline $\mathrm{S}_{6}$ & $\begin{array}{l}\text { Menjawab dengan menggambarkan } 5 \text { buah kantong yang setiap } \\
\text { kantongnya diisi oleh } 3 \text { buah permen dan diperjelas dengan } \\
\text { penjumlahan } 3+3+3+3+3=14 \text {, sehingga jawaban } S 6 \text { adalah } 14 \text {. } \\
\text { Jawaban yang diharapkan adalah } 15 \text { buah permen. }\end{array}$ \\
\hline
\end{tabular}

Pada pengerjaan soal kedua (Q2), subjek enam (S6) Menjawab dengan menggambarkan (5) buah kantong yang setiap kantongnya diisi oleh (3) buah permen dan diperjelas dengan penjumlahan $(3+3+3+3+3=14)$. Pada (Q2) kali ini (S6) melakukan kekeliruan, yakni pada saat melakukan penjumlahan yang dimana seharusnya jawaban yang diberikan berjumlah (15). (S6) mungkin pada saat- saat tertentu sering mengalai kelemahan dalam berhitung sehingga menyebabkan kekeliruan pada hasil akhir yang diberikan.

3. Pertanyaan Ketiga $\left(Q_{3}\right)$

Tabel 3. Hasil Jawaban Q3

\begin{tabular}{|c|c|}
\hline Subjek & Kesulitan \\
\hline $\mathrm{S}_{5}$ & $\begin{array}{lllll}\text { Menjawab dengan } & 12 \times 3= & 36 & \text { dengan } & \text { cara }\end{array}$ \\
\hline & $\begin{array}{l}3+3+3+3+3+3+3+3+3+3+3+3=6+6=12+12=24+12=36, \\
\text { sehingga jawaban } 55 \text { adalah } 36 . \text { Jawaban yang diharapkan } \\
\text { adalah } 4 \text { buah permen disetiap kantongnya. }\end{array}$ \\
\hline
\end{tabular}

Pada pengerjaan soal ketiga (Q3), subjek lima (S5) menjawab dengan $(12 \times 3=36)$ dengan cara menuliskan $(3+3+3+3+3+3+3+3+3+3+3+3=)$ kemudian diuraikan $(3+3=6),(6+6=12),(12+12=24)$ sampai akhirnya $(24+12=36)$. Masih menggunakan teknik sebelumnya yakni penjumlahan. (S5) sebenarnya dapat melakukan perkalian dengan baik kali ini, tetapi jawaban yang diberikan masih belum sesuai dengan konsep yang diberikan. Maka kasus yang dialamiu oleh (S5) masih sama dengan yang sebelumnya, yakni kesulitan dalam mentransfer pengetahuan.

Dari ketiga soal yang diberikan kepada enam subjek yang telah di pilih, masih banyak yang mengalami kesulitan dalam materi perkalian ini. Karena setiap individu memiliki kesulitannya masing- masing dalam menyelesaikan sesuatu. Seperti hal nya dalam menyelesaikan pertanyaan soal matematika seperti ini, masih banyak siswa yang sulit mengerjakan sesuai dengan harapan. Kesulitan yang dimiliki berbeda- beda setiap individunya. Maka dari itu janganlah selalu menyamaratakan kemampuan setiap individu.

\section{SIMPULAN}

Hasil penelitian yang diperoleh bahwa masih banyak siswa yang memiliki kesulitan belajar pada materi perkalian ini, dari keenam siswa yang dijadikan sampel penelitian 2 siswa berkemampuan matematika rendah memiliki kelemahan dalam berhitung, 2 siswa berkemampuan matematika rendah dan 2 siswa berkemampuan matetatika sedang kesulitan dalam mentransfer pengetahuan, dan 2 siswa berkemampuan tinggi memiliki kesulitan dalam operasi visual. 
DAFTAR PUSTAKA

Depdiknas, (2013): Tujuan Pembelajaran Matematika Sekolah Dasar. Martini Jamaris. (2014) . Kesulitan Belajar. Bogor: Ghaila Indonesia.

Waskitoningtyas, Rahayu Sri (2016). Analisis Kesulitan Belajar Matematika Siswa Kelas V Sekolah Dasar Kota Balikpapan Pada Materi Satuan Waktu. Program Studi Pendidikan Matematika, Universitas Balikpapan

Yeni, Ety Mukhlis. (2015). Kesulitan Belajar Matematika Di Sekolah Dasar. Dosen FKIP Prodi PGSD : Universitas Almuslim 